\title{
Neuroactive steroids and the new decade
}

The term 'neurosteroids' started to be used in the 1980 s to indicate a family of steroids synthesised within the brain and regulating, via steroid receptors or other receptors, several brain functions. Later on, the term 'neuroactive steroids' was introduced to include those steroids that are not synthesised in the brain or are only partly metabolised (eg, the transformation of testosterone into oestradiol via the action of brain aromatase) but can interact with neural circuits. During the first two decades of the current century, the number of published papers in this field increased by 3620 (source PubMed, keywords neurosteroid* or neuroactive steroid*), demonstrating a continuous interest in this wide topic. Our international congresses, started at the beginning of the century, have covered the entire scope of this broad research field, and contributions to these biennial meetings have been published in a series of special issues for different journals. $^{1-9}$

The present special issue includes many of the invited lectures presented during the last edition of the "Steroids and Nervous System" meeting (Torino, February 2019), contributed as contemporary reviews or as original articles. The papers not only embrace classical themes such as gonadal steroids and glucocorticoids, but also very new topics such as the involvement of neuroactive steroids in the control of energy homeostasis and the development of translational models for a variety of neural diseases in which neuroactive steroids are implicated.

The paper by Ball et al $^{10}$ illustrates the multiple roles of testosterone with respect to regulating a highly specialised neural circuit (the avian song system) in both males and females. One of the central aspects of reproduction, the switch of oestradiol action from negative- to positive-feedback in the regulation of the gonadotrophin-releasing hormone system, is widely discussed in the paper by Moenter et al. ${ }^{11}$ Rapid, nonclassical effects of oestradiol on the basal cholinergic neurones in mice are discussed in the paper by Kim et $\mathrm{al}^{12}$, demonstrating the presence of a marked sex difference in oestradiol-induced nonclassical effects and the intracellular distribution of oestrogen receptors in cholinergic neurones of the basal forebrain.

Glucocorticoids are used clinically during pregnancy to prevent complications (ie, prematurity), with the recreational use of cannabis during pregnancy also increasing at the same time; the potential implications of co-exposure to these compounds on the developing brain and later neurodevelopmental consequences are discussed in the review by Franks et al. ${ }^{13}$ The study by Lesuis et $\mathrm{al}^{14}$ demonstrates that both corticosterone and $\beta$-adrenergic receptor activation may cooperate to increase hippocampal spine number.
A very promising new field of research is the involvement of neuroactive steroids in the control of metabolism. In particular, a review by Kammel and Correa ${ }^{15}$ elucidates the organisation of the hypothalamic ventromedial nucleus (VMH) with a particular emphasis on sexual differences involving the presence of phenotypically distinct and sexually differentiated neurone populations within the $\mathrm{VMH}$. In addition, oestrogenic regulation of glucose-excited neurones, as well as how this may affect glucose and energy homeostasis, is discussed by Hirschberg et al. ${ }^{16}$ The review by Hidalgo-Lanussa et al ${ }^{17}$ discusses the relationships between lipotoxicity (a consequence of obesity or of the metabolic syndrome) and the development of neurodegenerative diseases, such as Alzheimer's disease. In this review, a cellular and molecular mechanism is proposed to explain the neuroprotective effect of oestrogens. Finally, the experimental study of Freire-Regatillo et al. ${ }^{18}$ demonstrates that peripubertal male and female mice respond differently to short-term dietary changes in a manner different from that reported in adults. This is also interesting in view of the effects on metabolism and neuroendocrine circuits that some molecules termed metabolic disruptors, including several xenoestrogens or xenoandrogens, ${ }^{19,20}$ may have when exposure occurs in adult life or in early life.

The neuroprotective effects of neuroactive steroids have been discussed for a long time, although several promising translational models have only become available in recent years. These models may better elucidate the role of neuroactive steroids in neural diseases, and several were presented during the meeting and are collected in this special issue. The active form of vitamin $D$ (called calcitriol) functions as a steroid hormone acting via both genomic and nongenomic pathways. Calcitriol and other vitamin D analogues affect steroid hormone synthesis and/or signalling in the nervous system, as well as cell proliferation. The review by Norlin ${ }^{21}$ discusses the possible roles of vitamin D analogues as candidates for the future improved treatment of human glioma and possibly also other cancers of the nervous system.

Oestrogens have several functions in the brain. In particular, they may enhance extinction learning across species and are considered as risk factors that may slow or accelerate natural ageing processes in women. In the review by Hammond et $\mathrm{al}^{22}$ it is suggested that these neuroactive steroids may have a role in the treatment of post-traumatic stress disorder, particularly in women. The review by Miller et $\mathrm{al}^{23}$ indicates that studies on gonadal hormones as risk factors in humans require the follow up of diverse cohorts over long periods of time, as is currently under way at the Mayo clinic. Finally, several brain diseases are linked to alterations in mitochondrial function, and gonadal hormones may regulate the metabolism 
and synthesis of key phospholipids such as cardiolipin. These events could be related to the homeostatic and protective actions of steroids in neural cells, as well as to the manifestation of sex differences in neurodegenerative disorders. ${ }^{24}$ The involvement of progesterone in neuroprotection and immunomodulation in Parkinson's disease is described in a mouse model in the study by Jarras et al. ${ }^{25}$ Other neuroactive steroids are involved in complications of sleep deprivation, ${ }^{26}$ in the imbalance of inhibitory and excitatory actions during pregnancy that program for poor behavioural outcomes in a sex-dependent manner later in life,${ }^{27}$ in some psychiatric diseases such as Tourette's syndrome, ${ }^{28}$ and in the regulation of mitochondrial function in tauopathies. ${ }^{29}$

Finally, the review by Patisaul ${ }^{30}$ describes the first results of a large project (the FDA collaborative project, CLARITY-BPA) on the effects of bisphenol $A$, an endocrine disruptor acting principally as an xenoestrogen that is found in large amounts in the environment. In particular, in this review, the results obtained regarding the action of bisphenol A on both brain and behaviour are discussed.

In conclusion, the new decade of studies of neuroactive steroids will certainly be dedicated to the investigation of their basic properties and mechanisms of action; however, as seen in this special issue, it will also be the time to start clinical trials that aim to explore the real neuroprotective properties of these molecules and develop even more potent analogues.

\section{ACKNOWLEDGEMENTS}

We acknowledge the support of the Fondazione Cavalieri Ottolenghi, the University of Torino, the University of Milano, the Department of Neuroscience, Rita Levi Montalcini (Torino) and the Department of Pharmacological and Biomolecular Sciences (Milano). Finally, we thank Wiley and all the staff of the Journal of Neuroendocrinology for hosting this special issue.

$$
\begin{gathered}
\text { Giancarlo Panzica PhD, Professor }{ }^{1} \text { iD } \\
\text { Roberto C. Melcangi PhD, } \text { Professor }^{2} \text { iD }
\end{gathered}
$$

${ }^{1}$ Dipartimento di Neuroscienze "Rita Levi Montalcini", Neuroscience Institute Cavalieri Ottolenghi (NICO), Università degli Studi di Torino, Orbassano, Italy

${ }^{2}$ Dipartimento di Scienze Farmacologiche e Biomolecolari, Università degli Studi di Milano, Milan, Italy

\section{ORCID}

Giancarlo Panzica iD https://orcid.org/0000-0002-9302-4647

Roberto C. Melcangi (iD https://orcid.org/0000-0003-0861-8967

\section{REFERENCES}

1. Melcangi RC, Panzica G.Special issue - Neuroactive steroids in the third millennium - Proceedings of the First Meeting on Steroids and Nervous System - Held in Turin, Villa Gualino, 11-14 February 2001 - Introduction. Brain Research Reviews. 2001;37:1-2.

2. Melcangi RC, Panzica G. Steroids and the nervous system. Ann N Y Acad Sci. 2003;1007:1-5.
3. Melcangi RC, Panzica G. Neuroactive steroids: an update of their roles in central and peripheral nervous system. Psychoneuroendocrinology. 2009;34(suppl 1):1-8.

4. Melcangi RC, Panzica G. Editorial. J Steroid Biochem. 2016;160:1.

5. Melcangi RC, Panzica GC. Neuroactive steroids: old players in a new game. Neuroscience. 2006;138:733-739.

6. Melcangi RC, Panzica GC. Neuroactive steroids and the nervous system: further observations on an incomplete tricky puzzle. J Neuroendocrinol. 2013;25:957-963.

7. Panzica GC, Balthazart J, Frye CA, et al. Milestones on steroids and the nervous system: 10 years of basic and translational research. J Neuroendocrinol. 2012;24:1-15

8. Panzica GC, Melcangi RC. The endocrine nervous system: source and target for neuroactive steroids. Brain Res Rev. 2008;57:271-276.

9. Panzica GC, Melcangi RC. New perspectives for the action of steroids in the brain. J Neuroendocrinol. 2018;30:e12576.

10. Ball GF, Madison FN, Balthazart J, Alward BA. How does testosterone act to regulate a multifaceted adaptive response? Lessons from studies of the avian song system. J Neuroendocrinol. 2020;32:e12793.

11. Moenter SM, Silveira MA, Wang L, Adams C. Central aspects of systemic oestradiol negative- and positive-feedback on the reproductive neuroendocrine system. J Neuroendocrinol. 2020;32:e12724.

12. Kim S, Barad Z, Cheong RY, Abraham IM. Sex differences in rapid non-classical action of $17 \beta$-estradiol on intracellular signaling and estrogen receptor alpha expression in basal forebrain cholinergic neurons in mouse. J Neuroendocrinol. 2020;32:e12830.

13. Franks AL, Berry KJ, DeFranco DB. Prenatal drug exposure and neurodevelopmental programming of glucocorticoid signalling. J Neuroendocrinol. 2020;32:e12786.

14. Lesuis SL, Timmermans W, Lucassen PJ, Hoogenraad CC, Krugers HJ. Glucocorticoid and beta-adrenergic regulation of hippocampal dendritic spines. J Neuroendocrinol. 2020;32:e12811.

15. Kammel LG, Correa SM. Selective sexual differentiation of neurone populations may contribute to sex-specific outputs of the ventromedial nucleus of the hypothalamus. I Neuroendocrinol. 2020;32:e12801.

16. Hirschberg PR, Sarkar P, Teegala SB, Routh VH. Ventromedial hypothalamus glucose-inhibited neurones: a role in glucose and energy homeostasis? J Neuroendocrinol. 2020;32:e12773.

17. Hidalgo-Lanussa $\mathrm{O}$, Baez-Jurado E, Echeverria V, et al. Lipotoxicity, neuroinflammation, glial cells and oestrogenic compounds. J Neuroendocrinol. 2020;32:e12776.

18. Freire-Regatillo A, Fernandez-Gomez MJ, Diaz F, et al. Sex differences in the peripubertal response to a short-term, high-fat diet intake. J Neuroendocrinol. 2020;32:e12756.

19. Heindel JJ, Blumberg B, Cave M, et al. Metabolism disrupting chemicals and metabolic disorders. Reprod Toxicol. 2017;68:3-33.

20. Marraudino M, Bonaldo B, Farinetti A, Panzica G, Ponti G, Gotti S. Metabolism disrupting chemicals and alteration of neuroendocrine circuits controlling food intake and energy metabolism. Front Endocrinol (Lausanne). 2019;9:766.

21. Norlin M. Effects of vitamin D in the nervous system: special focus on interaction with steroid hormone signalling and a possible role in the treatment of brain cancer. J Neuroendocrinol. 2020;32:e12799.

22. Hammoud MZ, Foa EB, Milad MR. Oestradiol, threat conditioning and extinction, post-traumatic stress disorder, and prolonged exposure therapy: a common link. J Neuroendocrinol. 2020;32:e12800.

23. Miller VM, Jayachandran M, Barnes JN, Mielke MM, Kantarci $\mathrm{K}$, Rocca WA. Risk factors of neurovascular ageing in women. J Neuroendocrinol. 2020;32:e12777.

24. Acaz-Fonseca E, Ortiz-Rodriguez A, Garcia-Segura LM, Astiz M. Sex differences and gonadal hormone regulation of brain 
cardiolipin, a key mitochondrial phospholipid. J Neuroendocrinol. 2020;32:e12774.

25. Jarras $H$, Bourque $M$, Poirier AA, et al. Neuroprotection and immunomodulation of progesterone in the gut of a mouse model of Parkinson's disease. J Neuroendocrinol. 2020;32: e12782.

26. Frau R, Traccis F, Bortolato M. Neurobehavioural complications of sleep deprivation: shedding light on the emerging role of neuroactive steroids. J Neuroendocrinol. 2020;32:e12792.

27. Shaw JC, Crombie GK, Zakar T, Palliser HK, Hirst JJ. Perinatal compromise contributes to programming of GABAergic and glutamatergic systems leading to long-term effects on offspring behaviour. J Neuroendocrinol. 2020;32:e12814.

28. Cadeddu R, Backstrom T, Floris G, Nordkild P, Segerdahl M, Bortolato $\mathrm{M}$. Isoallopregnanolone reduces tic-like behaviours in the D1CT-7 mouse model of Tourette syndrome. J Neuroendocrinol. 2020;32:e12754.

29. Grimm A, Lejri I, Halle F, et al. Mitochondria modulatory effects of new TSPO ligands in a cellular model of tauopathies. J Neuroendocrinol. 2020;32:e12796.

30. Patisaul HB. Achieving CLARITY on bisphenol A, brain and behaviour. J Neuroendocrinol. 2020;32:e12730. 